\title{
2 Assessment of the Atmosphere Composition After 3 Washing, Gas-freeing and Aerating Processes in 4 Vessel Cargo Tanks
}

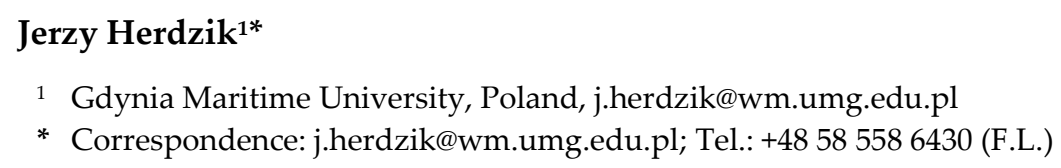

\begin{abstract}
Paper discussed the problem of atmosphere composition assessment after gas-freeing and ventilation of vessel cargo tank after washing process in aim to the entrance and its inspection. Correct assessment of atmosphere before the entrance into the cargo tank or other enclosed spaces is a basic condition for the possibility of safe work of a crew. It should be done following actions: assessment of the flammability hazard, the presence of other toxic or dangerous gases for human and oxygen concentration. In this aim the ship-owner should prepare adequate procedures: before entrance, during work and in emergency situations. On a vessel the assessment performs responsibility (entitled) officer whose decisions are crucial for the safety of prosecuting operations. The one of primary problem is proper (adequate) assessment of oxygen concentration in the air into cargo tank or enclosed space after the measurement which should be properly interpreted. It concerns basically such situations when the oxygen concentration into the tank after measure leads the value over $22 \%$ and below $20.6 \%$ of volume (mole) contribution (v/v).
\end{abstract}

Keywords: vessel cargo holds, tank washing, gas-freeing, aerating, atmosphere composition, assessment of safe atmosphere

\section{Introduction}

The washing process of cargo tank is a very important procedure during vessel operation. It distinguishes two basic stages of washing: prewashing and essential washing. It allows to reach the proper purity of cargo tank enabling the loading of next (another type) cargo. As well in the aim to take the same type of cargo it should be done the washing to remove the residues and sediments which decrease the active volume of tank capacity and to reach the inert atmosphere inside cargo tank into consideration of explosion threat during the ballast voyage. The preparedness of cargo tank for entrance of vessel crew to enclosed spaces requires the proper aerating (ventilation) to reach the safe atmosphere for work $[1,2]$.

The prewashing process of oily tankers (crude oil washing method) should be prosecute in inert atmosphere. Due to unloading operation and decreasing the level of liquid inside the tank in the aim of keeping the overpressure (about $4 \div 8 \%$ over the ambient) it holds by filling in the inert gas and controls the oxygen concentration (in the inert gas should be in the range of $0.5 \div 5 \%$, in cargo tank always below $8 \%$ ).

The final washing is done by using fresh water (sometimes with additives of permitted washing agents) supplying under pressure (about $0.8 \div 1.6 \mathrm{MPa}$ ) to washing machines system. After completing the washing process the slops are transferred to slop tanks and next for their treatment or pumped to port facilities. The tank atmosphere consists mainly hydrocarbons and hydrogen sulfide and other chemical substances from transported cargo, the components of inert gas what causes it dangerous for people $[3,4]$. 
The gas-freeing process (removing the gas residues from cargo) with using the inert gas has an aim to decrease the concentration of dangerous gases (hydrocarbons) below the required level (about $2 \div 4 \%$ ). To reach the near $0 \%$ would be time-consuming and basically impossible to achieve. After the process cargo tanks should be gas free.

The next process step depends on the target to reach. Tank should be aerated till the atmosphere will be correct for people entrance. Reaching the level (hydrocarbons concentration about $2 \div 4 \%$ depending on the realized procedure) allows on changing over the vans of inert gas system on atmospheric air ventilation. During from a few to several dozen hours it is possible on to achieve the tank atmosphere approximate the same like atmospheric. Before the people entrance in to a tank it should be done the assessment of atmosphere composition $[5,6,7,8,9,10]$. It should be safe for people work inside.

\section{Safe atmosphere into cargo tank for human entrance}

The proper procedures (required and approved by the ship-owner) should be performed which allows to assess the tank atmosphere as safe for the crew. The basic threats which may exist in cargo tank (enclosed space) after washing, gas-freeing and aerating are as follows [2,7,9]:

- hydrocarbon explosion - it requires the hydrocarbons concentration below 10\% (in some procedures below 5\%) of low explosive concentration (LEL);

- human toxicity - toxic substances for people and their toxicity levels. The main threat is coming from hydrogen sulfide $\left(\mathrm{H}_{2} \mathrm{~S}\right)$. The assessment of tank history operation should be checked in searching the other possible toxic substances for human;

- $\quad$ oxygen concentration in the range of $20.6 \div 22 \%$ in dry air.

It should be taking into account the types of tank operations. In the case of possibility to occur other substances (gases) they should be checked under the hazards for human. It is making use from information inserting in material safety data sheet (MSDS) for the evaluation of detected substances $[2,3]$ where is the information (among others) about the required actions during emergency procedures.

MSDS contains the following information (according to Commission Regulation of the European Union No. 2015/830 named REACH from 28 $8^{\text {th }}$ of May, 2015) [11]:

- identification of the substance/mixture and of company/undertaking;

- hazards identification;

- composition/information on ingredients;

- first aid measures;

- firefighting measures;

- personal precautions, protective equipment and emergency procedures;

- handling and storage;

- exposure controls/personal protection;

- physical and chemical properties;

- stability and reactivity;

- toxicological information;

- ecological information;

- disposal considerations;

- transport information (among others UN number);

- regulatory information;

- other information.

Procedures approved by ship-owner (or charterer) are obligatory on vessels in accordance with state maritime administration which flag the vessel raising, additionally in accordance with classification society requirements (every vessel should be in technical supervision) and in international shipping with the International Maritime Organization (IMO) [12].

\section{Assessment of hydrocarbon concentration in the atmosphere into cargo tank}


The aerating operation of cargo tank passes off through the forced ventilation with vans utilization of inert gas system without the necessity of keeping the tank overpressure. It is done through atmospheric air without any thermal-humid processing. The real state of tank atmosphere is a derivative of cargo and inert gases and atmospheric air. After finishing the process (stopping the vans) minimum 30 minutes is needed for homogenization the atmosphere (the fully homogenization will be achieved after a few days) before the measurement and assessment the tank atmosphere [2,13]. The hydrocarbons concentration assessment should be done by using the attested and checked explosimeters. The measurement performs on three different heights in the tank: the upper, the middle and at bottom due to the tank atmosphere impurity and different gases density in comparison to air. The methane gases are lighter than air over the equilibrium temperature (about $\left.-112^{\circ} \mathrm{C}\right)$, ethane and ethylene gases has the specific density on the level about 1 , hydrocarbons gases like: propane, butane, butadiene etc. are heavier than air. Two types of explosimeters are used: for the range $0-10 \%$ of low explosive limit (LEL) and for the range $0-100 \%$ of LEL [14]. It allows for the assessment the level of explosion and flammability hazard. After performed measurement the result means:

- $\quad$ over $30 \%$ of LEL as the explosion or fire is possible (due to tank impurity);

- in the range $10-30 \%$ of LEL as a potential existing hazard, the hot work is prohibited;

- below $10 \%$ of LEL (sometimes some procedures require below 5\%) in all measure points as without the explosion hazard (the others are still possible) [1].

As a principle it must not enter to any enclosed spaces when the concentration of explosive gases in the atmosphere is over 1\% of LEL. For the crude oil and its products the real volume concentration of hydrocarbon gases below 1\% of LEL is outside the hazard of explosion in any case but the toxicity hazard may still exist. It is considered that the total hydrocarbons volume concentration (as a hydrocarbon mixture derived from crude oil gases) in the air below $0.1 \%$ (or 1000 ppm) of LEL is outside the toxicity threshold hazard (in use are: TLV, MAC, NDS, PEL). The thresholds for Threshold Limit Value - Time Weighted Average (TLV-TWA) are as follows [15,16]:

- for methane

- for ethane

- for propane

- for butane

- for ethene (ethylene)

- for butadiene

- for benzene

- for carbon oxide

$$
\begin{aligned}
& 1000 \mathrm{ppm}(0,1 \% \mathrm{v} / \mathrm{v}) ; \\
& 900 \mathrm{ppm} ; \\
& 800 \mathrm{ppm} ; \\
& 600 \mathrm{ppm} ; \\
& 200 \mathrm{ppm} ; \\
& 10 \mathrm{ppm} ; \\
& 1 \mathrm{ppm} ; \\
& 50 \mathrm{ppm} \text {. }
\end{aligned}
$$

The data concerns to above mentioned hydrocarbons performing independently. Of course in the case of gas mixture the toxic action is a sum of components but it is not known the principles of summing. In dumbing down it may be the arithmetic summing because it is not known the effects (for above mentioned hydrocarbons) which will confirm the synergic action. Explosimeters essentially measures the explosive gases concentration as a sum without the contradistinction on type of hydrocarbon [14].

Reaching the volume concentration of oxygen in tested atmosphere in the range of $20.6 \div 21.0 \%$ is adequate for dilution the rested gases during aerating process to the permissible range (below TLV-TWA it means for forty equivalent hours of work week).

It is not allowed to depend on own senses (sight, smell) in the aim of assessment the possibility of safe work in enclosed spaces. Many gases (i.e. alkans) are colorless and scentless. It may be reasons of the dangerous occurrences. It recommends the use of devices for the atmosphere assessment in accordance with the Regulations of International Maritime Organization (IMO) MSC.1/Circ.1477 [12,14].

\section{Assessment of hydrogen sulfide concentration in the atmosphere into cargo tank}

The presence of hydrogen sulfide $\left(\mathrm{H}_{2} \mathrm{~S}\right)$ in the atmosphere of cargo tank after the aerating process is caused by the gas presence in the crude oil (is solved) and next the process of its degassing. 
In despite of the degassing requirement of crude oil the process declines during the cargo transport and may reach the level over a thousand ppm. The second phenomenon declines at the same time is the production of hydrogen sulfide during cargo transport. It is induced the presence of sulfur compounds in cargo which in presence of water (steam or vapor as gas humidity) and the iron (iron alloys i.e. steels) as catalysator are processed to hydrogen sulfide. The crude oil is a natural product (feedstock) may include the strains of anaerobic bacterium which may produce that gas as a product of their matabolism.

It is considered that the maximal hydrogen sulfide concentration for forty equivalent hours of work week is up to $5 \mathrm{ppm}$ (over twenty years ago the limit was $10 \mathrm{ppm}$ ). In spite of strong odor gas (from concentration about $0.5 \mathrm{ppm}$ ) the human smell is deactivated in very short time and the gas is getting impalpable. At very high concentration of $\mathrm{H}_{2} \mathrm{~S}$ is again impalpable which may the reason that human smell do not react at all. It should be mentioned that TLV-STEL (short time exposure limit) is $15 \mathrm{ppm}$ for $\mathrm{H}_{2} \mathrm{~S}$ it means the maximal time of human work is up to 15 minutes every hour with next 1 hour rest. TLV-C (ceiling threshold limit) is $30 \mathrm{ppm}$ and TLV-IDLH (threshold limit value immediately dangerous for human life and health) is only $300 \mathrm{ppm}$ (at the most about 15 minutes for survival). The concentration of hydrogen sulfide over $700 \mathrm{ppm}$ caused the quick consciousness loss and the life loss of human after a few minutes $[6,8,15]$.

Hence the toxicity hazard from hydrogen sulfide is very serious for human. In all cases of doubtfulness it should be done the verifying measure.

\section{Assessment of oxygen concentration in the atmosphere into cargo tank}

The atmosphere composition of dry air is presented in the table 1 . In real states the air composition may be different due to dilution the main components through other gases (contaminated gases). Water vapor is the most shared gas which is not mentioned in Table 1. Due to different concentration of water vapor depending on the air humidity the air composition will still change and so it is in a reality. The air humidity is measured and indicated as absolute or relative. The quantity of water vapor depends on the air temperature and its relative humidity. In case of saturated air $\left(100 \%\right.$ relative humidity, the reaching of dew point) at $+40{ }^{\circ} \mathrm{C}$ of air temperature it is 50.5 g $\mathrm{H}_{2} \mathrm{O} / \mathrm{m}^{3}$ but at $-40^{\circ} \mathrm{C}$ it is only about $0.5 \mathrm{~g} \mathrm{H}_{2} \mathrm{O} / \mathrm{m}^{3}$ [17]. The difference between two mentioned points is about a hundred times. The presence of water vapor dilutes the concentration of all atmospheric gases including oxygen.

Table 1. Dry air composition $[1,18,19]$.

\begin{tabular}{ccc}
\hline Symbol & Name & $\begin{array}{c}\text { Concentration } \\
{[\%][\mathbf{v} / \mathbf{v}]}\end{array}$ \\
\hline $\mathrm{N}_{2}$ & nitrogen & 78.048 \\
$\mathrm{O}_{2}$ & oxygen & 20.947 \\
$\mathrm{Ar}$ & argon & 0.934 \\
$\mathrm{CO}_{2}$ & carbon dioxide & 0.041 \\
$\mathrm{Ne}$ & neon & 0.001818 \\
$\mathrm{He}$ & helium & 0.000524 \\
$\mathrm{CH}_{4}$ & methane & 0.00017 \\
& other gases & the rest to $100 \%$
\end{tabular}

At high air temperature (over $+30^{\circ} \mathrm{C}$ ) and high relative humidity the oxygen dilution may be essential. The influence of oxygen concentration on human health and a possibility of her/his work in enclosed spaces is presented in Table 2.

Table 2. Oxygen concentration in cargo tank atmosphere versus human health $[6,14]$. 


\begin{tabular}{|c|c|}
\hline $\begin{array}{c}\text { Oxygen } \\
\text { concentration } \\
{[\%][v / v]}\end{array}$ & $\begin{array}{l}\text { The hazards for human health depending on oxygen } \\
\text { concentration in the atmosphere }\end{array}$ \\
\hline$>22$ & $\begin{array}{c}\text { prohibition of entrance, enriched atmosphere in oxygen, } \\
\text { increased the fire hazard, the human reaction - state of excitation } \\
\text { and euphoria; }\end{array}$ \\
\hline $\begin{array}{c}20.6 \div 22 \\
\text { or } 20.6 \div 21\end{array}$ & $\begin{array}{l}\text { the possibility of human entrance to enclosed space if no any } \\
\text { additional hazards exist, human reaction - natural; }\end{array}$ \\
\hline 19.5 & $\begin{array}{l}\text { prohibition of entrance, decreased oxygen concentration of } \\
\text { the atmospheric air in tank, human reaction - speeding up the } \\
\text { breathing, little difficulties in breathing, threat of loss the } \\
\text { conscious during the work of high intensity; }\end{array}$ \\
\hline 16 & $\begin{array}{l}\text { prohibition of entrance, significantly worsened the ability of } \\
\text { stocktaking, difficulties in breathing, human reaction - the } \\
\text { possibility of quick conscious loss without extortion prohibition of } \\
\text { entrance, breathing with strong difficulties; }\end{array}$ \\
\hline$<11$ & human reaction - a loss of live in a few minutes. \\
\hline
\end{tabular}

The oxygen insufficiency leads to the loss of conscious and the threat of life loss (human death). The reasons of oxygen deficiency in cargo tank may be different: oxidation processes which using the oxygen from air (i.e. tank corrosion), biochemical processes in transported cargo, works carried out inside cargo tank (i.e. welding), unproper aerating process (pockets in the tank volume where the ventilating air did not reached them, gases of bigger density than air, unproper direction of ventilation etc.).

\section{A necessity of oxygen correction of the atmosphere composition into cargo tank}

In manuals concerning to the safety of work in enclosed spaces $[5,6,9,10,17,19]$ they dish up a different oxygen concentration (in the range $18.5 \div 22 \%$ ) which is allowed the possibility of human work but why are there so essential differences.

The proper oxygen concentration should be in the range $20.6 \div 21 \%$ [6] but this does not give the guarantee that the atmosphere is real safe due to possible another hazards (see Table 2), on other hand the concentration in the range $18 \div 20.6 \% \mathrm{O}_{2}$ may be adequate for the safe work in some situations.

The oxygen concentration below $20.6 \%$ means that the oxygen insufficiency exists and it should be recognized the reason of such situation. The oxygen concentration correction should be done when the oxygen measurement was done at air temperature over $+30^{\circ} \mathrm{C}$ and at high air relative humidity. In such conditions the range of $20.6 \div 21 \% \mathrm{O}_{2}(\mathrm{v} / \mathrm{v})$ may be impossible to reach. The oxygen concentration has reached the maximal possible value and the atmosphere is safe under conditions from table 2 .

The dilution effect of oxygen concentration through water vapor was presented in Figure 1. 


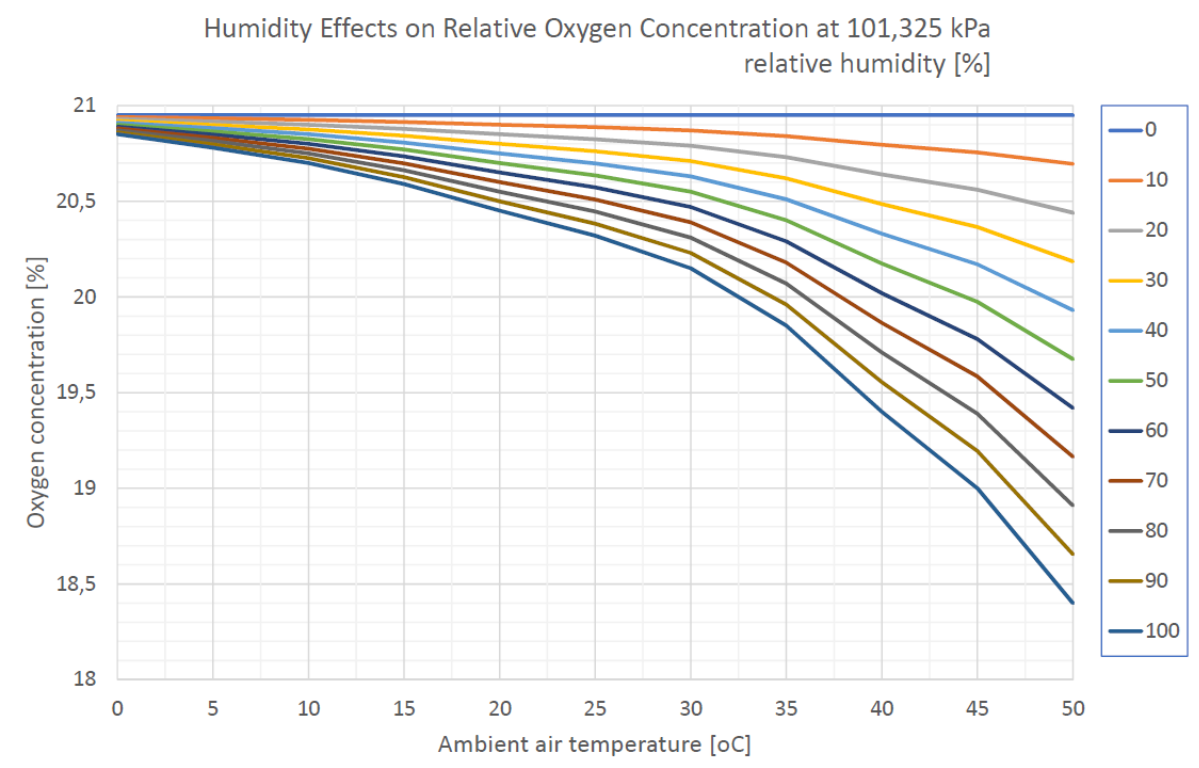

Figure 1. An influence of air humidity on the volume (mole) concentration of oxygen in dependence of ambient temperature at air pressure 101.325 $\mathrm{Pa}$ [own graph].

Figure 2 presents the correction factor of oxygen concentration in dependence of air temperature and humidity (for relative humidity of air the dependency is linear - it results from the definition of relative humidity).

Humidity and temperature correction factor of oxygen concentration [\%] air temperature [oC]



Figure 2. An influence of air temperature on the volume (mole) concentration of oxygen in dependence of humidity at air pressure 101.325 Pa [own graph].

At relative humidity $0 \%$ the volume (mole) concentration of air components is identical as for dry air (table 1). The air temperature has no influence on oxygen concentration and the amount is $20.947 \%$ (also the correction factor for oxygen concentration is zero).

The situation is different for humid air especially when the air temperature is above $+20^{\circ} \mathrm{C}$ and relative humidity over $70 \%$. From that point the oxygen concentration is below the level $20.6 \%$. For example at $+35^{\circ} \mathrm{C}$ and relative humidity $80 \%$ the maximal oxygen concentration possible during aerating process is $20.07 \%$ and the correction factor $0.87 \%$. It means that after the measurement in such conditions the result should be corrected through adding the value $0.87 \%$ (such oxygen concentration will be for dry air). In extreme case at $+45^{\circ} \mathrm{C}$ and air humidity $80 \%$ will be maximal $19.39 \%$. This is a reason why in some procedures the lower acceptable oxygen content is on the level 
of $19 \%$. The human reaction in humid hot air that the air is muggy. The increased temperature and its humidity over the thermal comfort condition for human limits his/her work productivity $[1,5]$.

Also the ambient air pressure has essential influence on human oxygen concentration feeling and the productivity of work (especially the rapidity of change the air pressure). Change atmospheric air pressure at the same temperature causes the change of air density and consequently the absolute amount of oxygen. According to Clapeyron's equation at isothermal change the gas density (air and oxygen) is directly proportional to gas absolute pressure.

In case of work on vessels it should be considered that the atmospheric air pressure is as on the sea level. There is no problem with the elevation (the air pressure is decreasing with the increased altitude - what may be essential meaning during work in the mountains - an increased in case of depression).

It may occur a phenomenon that inside high-pressure zone humans feel better (easier to breathe) and on the other hand inside the low-pressure zone the breathing is more difficult (as oxygen deficiency). Peoples particularly sensitive (meteoropathics) may feel heavy discomfort although the atmospheric conditions should be considered as being in standard for the others.

\section{Oxygen concentration correction factor}

The essential problem to be solved is to find the correction factor for the oxygen concentration in case of high air temperature or high relative humidity. In Figure 3 it may be read the correction factor between the oxygen concentration for dry air and humid air at dew point $(100 \%$ relative humidity). In case of partial humidity the correction factor will be partial also. For example for $50 \%$ of air humidity the correction factor (CF) will be the half (0.5) of CF read from Figure 3. To the air temperature below $+30^{\circ} \mathrm{C}$ the $\mathrm{CF}$ is low (below $1 \%$ ) but important to take into account during performing the enclosed space procedures $[2,6,10]$.

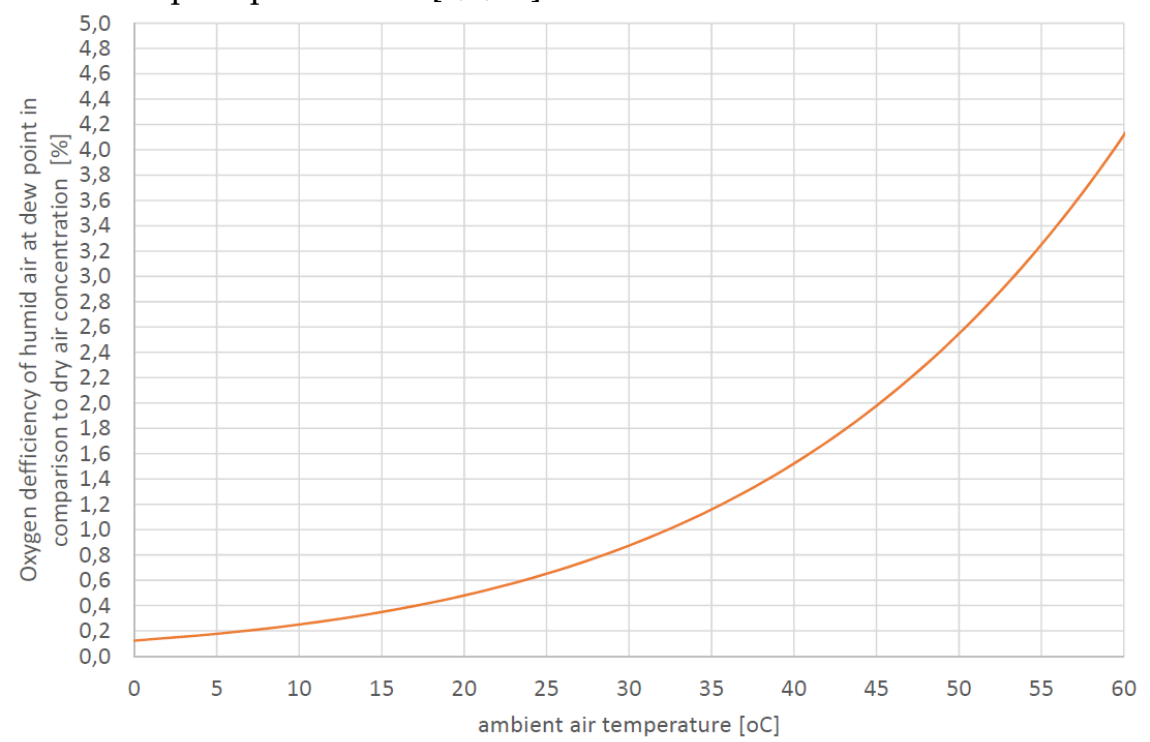

Figure 3. The oxygen deficiency in saturated air (at dew point) at pressure $101.325 \mathrm{~Pa}$ in dependence of ambient air temperature [own graph].

In aim to constraint the necessity of application the correction factor it should be done through decreasing the air temperature and efficiently through decreasing the air humidity. It may be done by using a thermal-humidity processing of ventilating air. It may be possible in inert gas systems where there is such processing available. Before the cargo operations on chemical tankers especially on gas tankers the atmosphere inside the cargo tank must be considered as inert and below required dew point. The dew point constricts the maximal possible amount of water vapor what has crucial significance for the safety of carried cargo with consideration on possible water-cargo reactions (creation of hydrates) and the risk of water freezing when the temperature of cargo will be below $0^{\circ} \mathrm{C}$. 
A thermal-humidity processing does not occur in inert gas systems on oily tankers. There is no technical possibility for decreasing the dew point. It remains practical possibility - ventilating the cargo tank in such time of a day when the ambient air conditions are the best for such process.

\section{Analysis of methane-oxygen-inert gas mixtures diagram and the threat of explosion}

The threat of explosion may occur when the flammable gas, oxygen and inert gases (mainly nitrogen, carbon dioxide, argon) mixtures are inside the explosion limits. The range of explosion changes depending on the oxygen and inert gas concentration. Figure 4 presents the diagram (as ABD triangle) for methane-oxygen and inert gases mixtures. Possibility of explosion exists only in the red area. It was written additional line of stechiometric components between methane and oxygen. In practical use only the $A B C$ triangle is essential. It means that by methane diluting the air makes the explosive range from $5.4 \%$ up to $14 \%$ (for boil-off gas from liquefied natural gas is from $5 \%$ up to $15 \%$ ) [16].

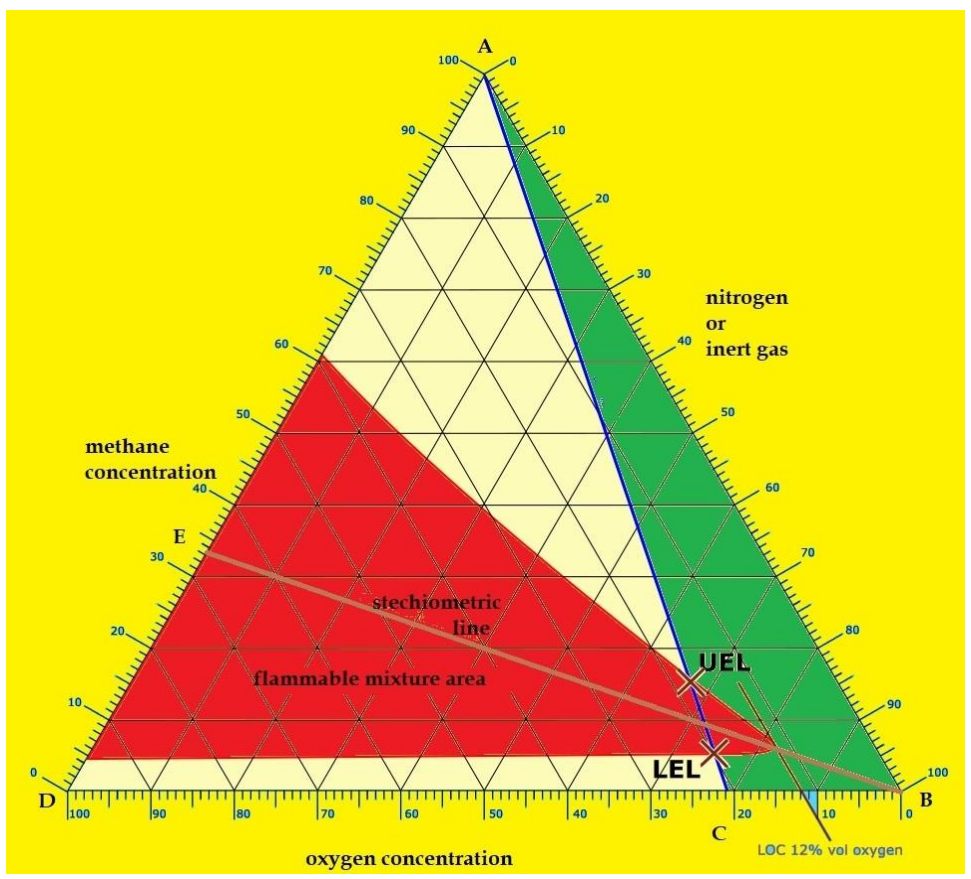

Figure 4. Diagram of methane-oxygen-inert gas mixtures [own graph].

When the oxygen concentration decreases the range narrows down and below the $12 \%$ concentration of oxygen the explosion (for methane-air mixtures) does not occur in all green area of $\mathrm{ABC}$ triangle. For all types of cargo operations the atmosphere in the tank, inside the green area, is safe but the procedures say that the oxygen concentration should be below $8 \%$ (due to measure error and differences in composition of the atmosphere in different places of tank volume) ensures the safety.

\section{An influence of ambient temperature on work conditions into cargo tanks}

It may be considered that in the ambient air temperature range $5 \div 20^{\circ} \mathrm{C}$ exists the possibilities for human work dressed in proper overall when are fulfilled appropriate work conditions (i.e. continuous ventilation, accessory of work place, precaution anti falling) and assuring human thermal comfort. Air temperature behind the mentioned range may create additional threats.

When the ambient air temperature is below $+5^{\circ} \mathrm{C}$ and the ventilation system works (air flow) it may be felt the sense of cold and hypothermia. At temperatures below $0^{\circ} \mathrm{C}$ it happens earlier. The basic solution is a use the hot air ventilation what improved the work conditions without the necessity of work breaks for getting warm. The other ones are the limitation of work time, using better work overalls, work breaks for warming, using hot drinks or meals etc. 
Too long time dwelling in environment wherein is extremely low temperature may result in occurring of hypothermia conceived threat for human life. The symptoms of hypothermia are: nausea, quick extortion, headache and head giddiness, tendency for aggravation or euphoria. The first symptoms are shivers which are the reaction of human organism as a compensation of body temperature decreasing. This is a probe of creation additional amount of heat from energy stock in human body. Frostbites are dangerous especially of protruding parts of human body (nose, ears, fingers and toes) $[5,10]$.

The more often case is a work at too high ambient temperature over $+30^{\circ} \mathrm{C}$ (sometimes over $+40^{\circ} \mathrm{C}$ e.g. in fuel centrifuges room on vessels). The self-regulation of human body through the perspiration phenomenon has a limited possibility. Basically the cooling effect through perspiration are decreasing with ambient air temperatures over the human body temperature about and over $+36.6^{\circ} \mathrm{C}$. Person working at high ambient air temperatures loses water with sweat and mineral salts. A loss of water and mineral salts should be leveled out through water drinking and salts ingestion. A drinking of about one liter of water during one hour is the highest function of healthy human being. It should be done through drinking a small amount of water in short intervals of time. The good solution is taking special drinks (isotonic) which may recompence the loss of mineral salts. The threat for human is a disturbance of electrolyte balance which conditioned the proper heart state. If imbalance happens it may appear risk of heart twitching, the threat of seizures and heart rhythm disturbances, changes in blood pressure, confusions etc. It is not allowed an ingestion the salts in tablets it is a necessary to solve tablets in water. Do not drink any alcohols because they increase water excretion from human organism. It is important the work planning in such atmosphere conditions when they are the most suitable for humans (e.g. during nights) or with time limitation, often breaks in work and no work at midday hours etc.

\section{Required work conditions into enclosed spaces by maritime regulations}

It may be considered that in the ambient air temperature range $5 \div 20^{\circ} \mathrm{C}$ exists the possibilities for human work dressed in proper overall when are fulfilled appropriate work conditions (i.e. continuous ventilation, accessory of work place, precaution anti falling) and assuring human thermal comfort. Air temperature behind the mentioned range may create additional threats. Frostbites are dangerous especially of protruding parts of human body (nose, ears, fingers and toes) $[5,10]$.

The fulfillment the requirements for proper and safe air composition for human work is the preliminary condition to next preparations for the human entrance to enclosed spaces. The next preparations should ensure the possibility of safe work in dependence of type of work and other requirements of procedures like:

- the assurance of other human supervision (including connection means between the worker and supervisor) and the reassurance of person working in enclosed space;

- the equipment preparation on case of emergency situations (breathing apparatus, lifeline, evacuation line etc.) - emergency procedures;

- continuous gas detection required the concentration control (including portable personal oxygen concentration detector and/or explosimeter);

- continuous ventilation of volume tank, at some works (e.g. welding) the application of extractor fans (welding fumes and dusts);

- other requirements according to the procedures being in force.

An example of proper preparing the work place during welding process into the tank is presented in Figure 5. 


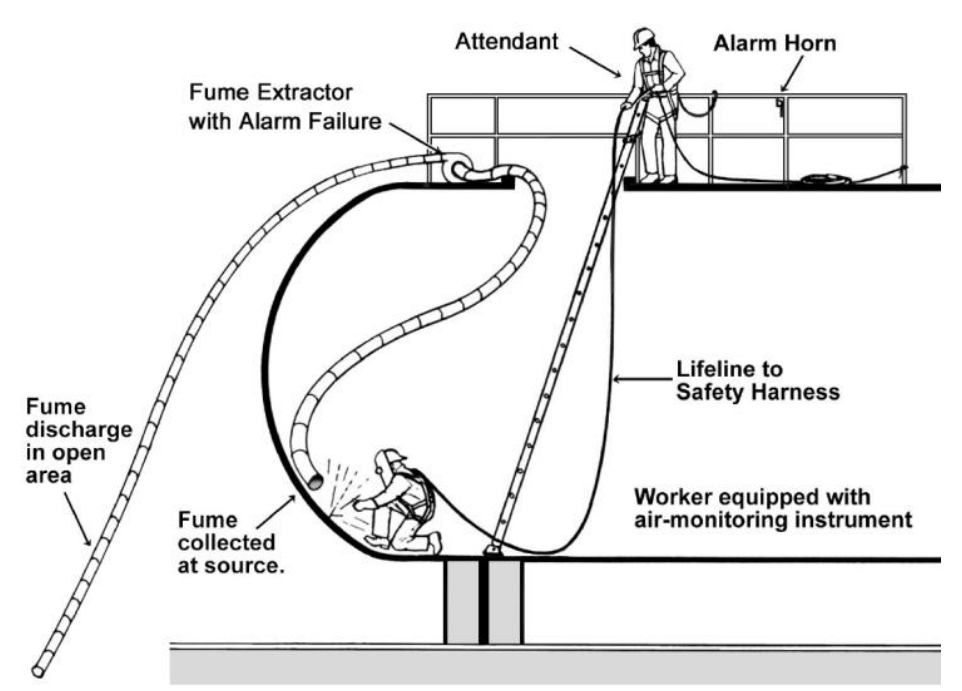

Figure 5. Essential conditions for allowing the work into enclosed spaces - the safety system [10].

\section{Discussion. Final remarks}

Author of that paper recognized the necessity of explanation the problems due to some interpreted doubts related to the information included in manuals concerning to the safety of entrance into enclosed spaces on vessels and the ship-owners procedures concerning to the safety precautions for preparing, entrance, protection and work inside the cargo tanks. The essential question is how to interpret the result of measurement the oxygen concentration in cargo tanks giving the guarantee of safe work. It may be found the information that the oxygen concentration in the range $18.5 \div 19 \%$ still gives the conditions for safe work and there is no mentioned about the upper limit. In other manual there is an interpretation that the safe oxygen concentration should be in the range $20.6 \div 22 \%$ (presented in Table 2).

The assessment of atmosphere composition in cargo tank after many different processes during preparing to loading, laden voyage, discharging, gas-freeing, aerating and others is a complicated problem and sometimes difficult for clear-cut answer. It is a necessity the verification and analysis of all processes dropped in. Even after fulfillment all necessary precautions in cargo tank still may exist the human factors: health state, age, time of rest, mood etc. which have the influence on human productivity of work. The final decision about the permission for work in enclosed spaces depends on the decision of responsibility officer (competent person). It must be remembered that the atmosphere composition still changes (human presence, prosecuted work, ventilation efficiency, moment of a daytime, external atmospheric conditions, change position of a vessel and others). Also the condition of safe work may change it must be still monitored with alarm when will be inappropriate. After determined intervals of time (often $4 \div 12$ hours) the atmosphere assessment and new procedure should be done again. Because many responsibility officers have some doubts the paper was prepared.

Supplementary Materials: The following are available online at: www.tso.co.uk, www.standard-club.com, www.youtube.com/watch?v=GqXMPvpwL10, www.draeger.com, www.mathesontrigas.com, www.tcf.com.

Funding: This research received no external funding.

Conflicts of Interest: The author declare no conflict of interest.

\section{References}

1. Code of Safe Working Practices for Merchant Seamen, Maritime and Coastguard Agency (MCA), 2010 (consolidated edition), changes 2018, www.tso.co.uk.

2. A master's guide to Enclosed Space Entrance, Standard Club, 2017, www.standard-club.com. 
3. HM 40 Guidelines for the Crude Oil Washing of Ship's Tanks and the Heating of Crude Oil Being Transported by Sea, Energy Institute, London, 2018.

4. https://www.youtube.com/watch?v=GqXMPvpwL10 (accessed 10 $0^{\text {th }}$ June 2019).

5. https://www.portalbhp.pl (Polish portal of work safety and hygiene, accessed $10^{\text {th }}$ June 2019).

6. Polish Register of Shipping, Polski Rejestr Statków, Wytyczne dotyczące bezpiecznego wejścia do przestrzeni zamkniętych, Publikacja Informacyjna Nr 28/I, July 2016 (in Polish).

7. International Safety Guide for Inland Navigation, Tank-barges and Terminals, Chapter 10, Enclosed Spaces, CCNR/OCIMF 2010.

8. Confined Spaces, CSBP-GM-11-031-52, version 14.0.0, CSBP 2017.

9. Code of Practice for Working in Confined Spaces, Health \& Safety Authority, 2002.

10. Construction Health \& Safety Manual, Chapter 33, Confined Spaces, www.ihsa.ca (entrance: $05^{\text {th }}$ August 2019).

11. Commission Regulation (EU) 2015/830, Registration, Evaluation, Authorization and Restrictions of Chemicals (REACH), 2015.

12. MSC.1/Circ.1477 - Guidelines to facilitate the selection of portable atmosphere testing instruments for enclosed spaces as required by SOLAS Regulation XI-1/7.

13. Hazards of oxygen-deficient atmosphere, Doc 44/18, European Industrial Gases Association AISBL, EIGA 2018.

14. https://www.draeger.com (accessed 10 th June 2019).

15. International Maritime Dangerous Goods Code - IMDG code, IMO, London 2017.

16. Lower and Upper Explosive Limits for Flammable Gases and Vapors (LEL/UEL), Reference Information, www.mathesontrigas.com (accessed 10 th June 2019).

17. Density Corrections for Moist Air and Other Gases (Information and Recommendations for the Engineers), Tween City Fan (TCF), FE-1700, 2017, www.tcf.com.

18. Mackenzie F.T., Mackenzie J.A., Our changing planet, Prentice-Hall, New York, 1995.

19. Bugbee B., Blonquist M., Absolute and Relative Gas Concentration: Understanding Oxygen in the Air, ICT, 2016.

\section{Acknowledgement}

This work was supported by fund of Gdynia Maritime University, grant no: WM/2019/PZ/03 